\title{
Influencia económica de las fábricas de tabaco en el surgimiento de negocio ${ }^{1}$
}

\author{
Bertilda Gutiérrez Cruz ${ }^{2}$ \\ Ludys Amparo Mejía Dávila ${ }^{3}$ \\ Martha Irela Lanuza Pastora ${ }^{4}$ \\ Beverly Castillo Herrera ${ }^{5}$
}

1 Este artículo presenta los resultados de la investigación titulada "Influencia económica de las fábricas de tabaco en el surgimiento de negocios formales e informales en la zona media del distrito III de la ciudad de Estelí en el año 2013" Las autoras defendieron su título de licenciada en administración de Empresas. 2013. UNAN-Managua, FAREM-Estelí.

2 UNAN-Managua, FAREM-Estelí. Correo electrónico:berthavanesa@hotmail.com

3 UNAN-Managua, FAREM-Estelí. Correo electrónico:davilaludys237@hotmail.com

4 UNAN-Managua, FAREM-Estelí. Correo electrónico:irelalanuza@yahoo.com

5 Maestría en Ciencias Sociales por la Universidad de Guadalajara, estudiante de doctorado en Ciencias Sociales por la Universidad del Zulia. Docente titular de la UNAN-Managua, FAREM-Estelí. Correo Electrónico: beverly. castillo@yahoo.com.

\section{RESUMEN}

Este estudio presenta la realidad del comercio formal e informal de la zona media del distrito III de la ciudad de Estelí y la manera que influyen las fábricas de tabaco en el surgimiento de estos. La investigación es de tipo aplicada y cuantitativa. El tipo de muestreo que se aplicó fue probabilístico, y se trabajó con la base de datos del registro de negocios formales de la Alcaldía Municipal de Estelí. Se aplicó una encuesta dirigida a los propietarios de negocios formales e informales, y se entrevistaron a algunos propietarios de negocios formales e informales y a trabajadores de las fábricas.

Los negocios informales surgen y se consolidan como resultado de la carencia de oportunidades laborales, los comerciantes no miran su negocio como una empresa rentable, al contrario lo consideran como una forma de sobrevivencia. En la mayoría de los negocios formales e informales no llevan un registro de las transacciones comerciales, carecen de financiamiento y toman decisiones basándose en la intuición y experiencia de sus propietarios. A partir de estos resultados, se identificaron las principales fortalezas, oportunidades, debilidades y amenazas de éstos negocios, lo que permitió sugerir una estrategia que conduzca a una mayor rentabilidad.

Palabras Claves: Fábricas de tabaco, Negocios formales, Negocios informales. 


\title{
Economic influence of the cigar factories in the emergence of new business $^{1}$
}

\author{
Bertilda Gutiérrez Cruz² \\ Ludys Amparo Mejía Dávila ${ }^{3}$ \\ Martha Irela Lanuza Pastora ${ }^{4}$ \\ Beverly Castillo Herrera ${ }^{5}$
}

\begin{abstract}
1 This article is based on the research titled Economic influence of the cigar factories in the emergence of new business. To obtain the title of Bachelor of Business Administration from the UNAN-Managua, FAREM-Estelí. 2 UNAN-Managua, FAREM-Estelí. E-mail: berthavanesa@hotmail.com

3 UNAN-Managua, FAREM-Estelí. E-mail: davilaludys237@hotmail.com

4 UNAN-Managua, FAREM-Estelí. E-mail: irelalanuza@yahoo.com

5 Master in Social Sciences from the University of Guadalajara, a PhD student in Social Sciences from the University of Zulia. Teaching holder of UNAN-Managua, FAREM-Estelí. E-mail: beverly.castillo@yahoo.com.
\end{abstract}

\begin{abstract}
This study presents the reality of formal and informal commerce the middle of the third district of the city of Esteli and the cigar factories influence in the emergence of these. The research is applied and quantitative type. The type of sample applied was probabilistic, and worked with the registry database formal business of the Municipal Mayor of Estelí. A survey of owners of formal and informal businesses was applied and interviewed some owners of formal and informal businesses and factory workers.

Informal businesses emerge and are consolidated as a result of the lack of job opportunities, merchants do not consider their business as a profitable enterprise, contrary consider it as a form of survival. In most formal and informal businesses do not keep records of business transactions, lack of financing and make decisions based on intuition and experience of its owners. From these results, the main strengths, weaknesses, opportunities and threats of these businesses, allowing suggest a strategy that will lead to greater profitability were identified.
\end{abstract}

Keywords: Cigar factories, Formal Business, Casual Business. 


\section{INTRODUCCIÓN}

La ciudad de Estelí se ha caracterizado desde los años setenta como productora de tabaco. Desde los años 90 se han incrementado la instalación de las fábricas de tabaco, en este período la ciudad no contaba con la infraestructura adecuada para albergar a las empresas de producto terminado (puro), por ello la mayoría se instalaron en casas que no prestaban las condiciones para desarrollar el trabajo y perjudicaban el medio ambiente.

En el marco de la política urbana del municipio de Estelí, la Alcaldía Municipal determinó que el área de crecimiento industrial de la ciudad se ubicara en el Distrito III. Uno de los problemas más grandes que enfrenta la industria tabacalera de Estelí, es la necesidad de locales especializados para desarrollar la labor tabacalera, por ello muchos empresarios han decidido invertir en la construcción de infraestructura más adecuada en el área designada para el crecimiento industrial.

La instalación de las fábricas en el Distrito III, ha permitido generar empleos que dinamizan la economía de esa parte de la ciudad. La mayoría de la mano de obra empleada se concentra en los trabajos de manufactura de este rubro, convirtiéndose desde hace años en un sector de mucha importancia para la economía local.

Con la generación de empleos por las fábricas de tabaco no solo se benefician los trabajadores de las empresas, sino a otras personas, que han creado sus negocios de servicios alimenticios, tiendas de ropa nueva y de segunda, salas de belleza, farmacias, distribuidoras, puestos de verduras, productos lácteos, pan, carpinterías, entre otros.

Los negocios formales se ven afectados por la competencia desleal de los negocios informales, ocasionando que sus ventas disminuyan por negocios que ofrecen los mismos productos y/o servicios. El comercio informal se da principalmente por la escasez de trabajo formal, porque las empresas de mayor tamaño no se dan abasto para contratar toda la mano de obra disponible en la ciudad. Los negocios informales carecen de apoyo y financiamiento, siendo menos competitivos ante negocios con mayor inversión y legalmente establecidos.

Los negocios formales e informales pocas veces buscan financiamiento en bancos, financieras $y$ organizaciones, ya que consideran que son muy exigentes con los requisitos de crédito, garantías, tasas de interés elevadas que reducen sus ganancias, convirtiéndose en la principal limitante para el desarrollo económico de dichos negocios, porque al carecer de capital de trabajo les impide realizar una mayor inversión para aumentar la oferta de sus productos y/o servicios.

Para determinar los antecedentes de esta investigación se consultaron las Bibliotecas de la Universidad Nacional Autónoma de Nicaragua (UNAN-FAREMEstelí), en la Universidad del Norte de Nicaragua (UNN), la Universidad Politécnica de Nicaragua (UPOLI), y el Movimiento de Mujeres Trabajadoras y Desempleadas (MEC). Se identificaron 3 tesis de estudio para optar al título de licenciatura y un diagnóstico. La investigadora MSc. Beverly Castillo (2007) realizó un diagnóstico ${ }^{1}$ sobre derechos humanos, laborales y de género de mujeres que laboran en las fábricas de tabaco de la ciudad de Estelí, entre los principales resultados, se destacan que en el año 2006 el 47\% de las mujeres que trabajan en las fábricas de producto terminado de tabaco se ubican entre las edades de 14 a 20 años, el $51 \%$ no tiene pareja estable, el $26 \%$ tienen estudios primarios y el $57 \%$ estudios secundarios. El $82 \%$ de las mujeres son el principal proveedor de la familia. El

1 Este diagnóstico fue para conocer los derechos humanos, laborales y de género de mujeres que laboran en las fábricas de tabaco por el Movimiento de Mujeres Trabajadoras y Desempleadas (MEC) y fue sustentada en el año 2007. 
$65 \%$ tienen un promedio de ingresos familiares a la quincena de $C \$ 500.00$ a C $\$ 1,000.00$ y un $30 \%$ de $C \$$ $1,001.00$ a $C \$ 2,000.00$.

Una primera tesis de Licenciatura ${ }^{2}$ la presenta Salina Gómez y Hernández Siles y se titula "Caracterización económica y legal del comercio informal de la Ciudad de Condega, 2009", reflejan que los negocios informales inician con ingresos propios de trabajos anteriores o de préstamos con familiares y/o financieras, los que a su vez son negocios ejercidos en su mayoría por mujeres.

Una segunda tesis ${ }^{3}$ fue realizada por Montalván Florián y Rodríguez Cruz (2011) y se titula "Situaciones económica y social que presenta el comercio informal en la avenida central de la ciudad de Estelí, 2011".Los principales resultados reflejan que los propietarios de estos negocios han buscado esta forma de trabajo como una fuente de sobrevivencia para sus familias, comprobando que el índice de desempleo en la ciudad de Estelí es del 15\%.

Una tercera tesis ${ }^{4}$ fue elaborada por Arévalo Espinoza, Gutiérrez Díaz y Moreno Altamirano. (2012) y se titula "Impacto económico generado por el empleo a los trabajadores del área de producción en la empresa manufacturera de tabaco Drew Estate tobacco company de la ciudad de Estelí, 2012". Los principales resultados demuestran que los trabajadores solteros gastan más en: artículos personales, servicios básicos,

2 Esta investigación fue para optar al título de licenciatura en Administración de Empresas por la Universidad Nacional Autónoma de Nicaragua (UNAN) y fue sustentada en el año 2009.

3 Esta investigación fue para optar al título de licenciatura en Administración de Empresas por la Universidad Nacional Autónoma de Nicaragua (UNAN) y fue sustentada en el año 2011.

4 Esta investigación fue para optar al título de licenciatura en Economía por la Universidad Nacional Autónoma de Nicaragua (UNAN) y fue sustentada en el año 2012. educación, recreación y otros, lo que garantiza, que estos trabajadores tengan hábitos de consumo diversos y con efectos mayores sobre su bienestar.

Los resultados de esta investigación servirán de apoyo a los propietarios de los negocios formales e informales, al Ministerio de Economía Familiar, Comunitaria y Cooperativa, al Ministerio de Fomento, Industria y Comercio (CAMIPYME), MIFIC/INPYME y al Programa de Desarrollo de la Micro, Pequeña y Mediana Empresa Nicaragüense (PROMIPYME), que realicen capacitaciones sobre registros contables, emprendedurismo y motivación, para que los microempresarios adquieran dichos conocimientos que son indispensables para permanecer en el mercado, y a los propietarios de las fábricas de tabaco.

Este estudio tiene como objetivo general determinar la influencia económica de las fábricas de tabaco en el surgimiento de negocios formales e informales de la zona media del distrito III de la ciudad de Estelí, en el año 2013.

\section{MATERIALES Y MÉTODOS}

La investigación es de tipo aplicada y cuantitativa. El tipo de muestreo que se aplicó fue probabilístico aleatorio simple, porque todos los negocios formales e informales tienen la misma probabilidad de ser elegidos. El universo lo constituyen 280 negocios formales y 45 negocios informales. Mediante el uso de métodos estadísticos se obtuvo una muestra de 162 negocios formales y 40 negocios informales, se trabajó con la base de datos del registro de negocios formales de la Alcaldía Municipal de Estelí, al mismo tiempo se realizó una visita en la zona para contabilizar el número de negocios informales debido a que no se cuentan con datos exactos por parte de la Alcaldía y DGI.

Se utilizaron fuentes primarias para la recolección de datos como encuestas y entrevistas semi- 
estructuradas, dirigidas a los propietarios de negocios formales e informales y a trabajadores de las fábricas. También se utilizaron fuentes secundarias como: libros, leyes, trabajos de grado, diagnostico e internet.

\section{RESULTADOS Y DISCUSIÓN}

Los resultados de esta investigación se han organizado en tres partes. El primero aborda los principales ejes conceptuales, la segunda parte el origen de las fábricas de tabaco en la ciudad de Estelí, y la tercera parte presenta los resultados obtenidos de la aplicación de los instrumentos.

\section{Los tres ejes principales de la investigación son:}

Las MIPYMES son todos aquellas micro, pequeñas y medianas empresas, que operan como persona natural o jurídica, en los diversos sectores de la economía, siendo en general empresas manufactureras, industriales, agroindustriales, agrícolas, pecuarias, comerciales, de exportación, turística, artesanales y de servicios entre otras. (MIFIC, 2008)

Las Zonas Francas son toda área del territorio Nacional de dominio público o privado, declarado como tal por el Poder Ejecutivo en el ramo de Hacienda y Crédito Público, bajo vigilancia fiscal, sin población residente, donde podrán establecerse y funcionar empresas que exporten su producción y/o servicios fuera del área centroamericana, sujeta al Régimen Aduanero Especial que se establece en su ley creadora y su reglamento. (Comisión Nacional de Zonas Francas, 2005)

Los Negocios es toda actividad de carácter mercantil y con ánimo de lucro. Cuando se manejan ciertos volúmenes de venta y un determinado nivel de organización, el negocio alcanza la categoría de empresa. (Andersen, 1997)

\section{El origen de las fábricas de tabaco en la ciudad de Estelí}

En las fábricas de tabaco, se paga en planilla 7, 000,000.00 de dólares anuales solo en la parte de fábricas de puro sin incluir campo, que equivale aproximadamente a 165,000,000.00 de córdobas que se mueven en el comercio anual, solo de salario directo en planilla; si se agrega prestaciones sociales aproximadamente $10,000,000.00$ de dólares al año, además de las inversiones que hace cada empresa en los servicios básicos agua, energía, etc., se podrá percibir que la zona franca del tabaco en Estelí específicamente, dinamiza la economía local de manera significativa.

Como responsabilidad social empresarial, las zonas francas del tabaco en Estelí apadrinan escuelas de educación especial, centro de jóvenes en riesgo, centro de desarrollo infantil, educación de adultos, ligas deportivas, obras comunales, colectas nacionales CONANCA, Teletón y Subastas anuales, esto representa un promedio de $3,680,000.00$ córdobas destinados a obras sociales, aparte de los convenios con los trabajadores en anteojos, préstamos personales y alimentación. La asociación de puros tiene como meta una clínica previsional solo para los trabajadores de las fábricas.

Actualmente en Estelí existen 35 grandes fábricas que manejan el proceso del tabaco hasta la producción de puros y emplean entre 15 y 18 mil personas. El 62\% del personal ocupado en este rubro son mujeres y solo el $38 \%$ varones. Si se considera todo el proceso productivo, incluyendo las fincas tabacaleras, son 30 mil personas que viven de la producción del tabaco.

Las fábricas de tabaco ubicadas en las zona media del distrito III a estudiar son: My Father, Plasencia, Tambor, Pensa, Perdomo, Valle de Jalapa, Olivas y Nacsa, las que actualmente generan 5,198 empleos directos en las diferentes áreas: producción, empaque, rezago y personal administrativo. 
Los salarios en las fábricas de estudio son similares, pero el $80 \%$ de los trabajadores ganan por producción, y solo el $20 \%$ ganan por día laborado, el cual se lo pagan a C\$ 130.00 córdobas.

El $70 \%$ de los trabajadores que ganan por producción tienen un salario aproximado de $C \$ 1,000.00$ a la semana y un $30 \%$ C\$ $1,500.00$ por semana. Los salarios de producción varían de acuerdo al tipo de capa, pedidos, puro, etc.

\section{Resultados obtenidos de la aplicación de los instrumentos.}

\section{Datos generales de los negocios formales e informales}

Mediante la información recopilada y analizada a través de los instrumentos se obtuvo que el $64 \%$ de los propietarios de los negocios formales son varones y el $36 \%$ son mujeres, en los negocios informales el $65 \%$ de los propietarios son varones y el $35 \%$ son mujeres, en su mayoría personas adultas entre las edades de 41-50 años.

El $20 \%$ de los propietarios de negocios formales y el $48 \%$ de los propietarios de negocios informales tienen únicamente estudios primarios, debido a la falta de recursos económicos.

Las personas con menor estudio poseen pocos conocimientos acerca de cómo administrar su negocio, esto no es una limitante para seguir con el funcionamiento, pero si les afecta en sus ganancias, porque tienen poca visión empresarial y toman decisiones basándose en la intuición y experiencia.

El $13 \%$ de los propietarios de negocios formales son procedentes de otros lugares, pero cuentan con su establecimiento permanente en este sector, a diferencia del $40 \%$ de los negocios informales que no pertenecen al distrito III, y solo se instalan para comercializar sus productos. Por ejemplo los que ofertan servicios alimenticios, se establecen en los periodos de desayuno y almuerzo, mientras que los comerciantes de ropa, calzado, bisutería, entre otros, solo llegan a instalarse el día de pago de los trabajadores de las fábricas, con lo que se demuestra la emigración de personas procedentes de otros lugares, por el potencial económico que se desarrolla en la zona.

El $86 \%$ de los negocios formales y el $55 \%$ de los negocios informales cuentan con un local propio, ya que la mayoría de los negocios son pulperías, las cuales son establecidas en las casas de habitación de los propietarios.

Los propietarios de negocios que tienen su propio local, se evitan de pagar alquiler lo que los hace más rentable, ofrecer precios más bajos, ejemplo de ello las tiendas de ropa y zapatos de segunda, por lo tanto tienen una mayor clientela.

El $68 \%$ de los propietarios de los negocios formales y el $30 \%$ de los propietarios de los negocios informales, iniciaron con una inversión superior a los 10,000.00 córdobas. (Ver cuadro $\mathrm{N}^{\circ} .1$ )

\begin{tabular}{|l|r|r|r|r|}
\hline \multicolumn{1}{|c|}{ Inversión inicial } & $\begin{array}{c}\text { Negocios } \\
\text { Formales }\end{array}$ & \multicolumn{1}{c|}{$\begin{array}{c}\text { Negocios } \\
\text { Informales }\end{array}$} & $\%$ \\
\hline De 3,500 a 4,500 & 21 & 13 & 23 & 58 \\
\hline De 4,501 a 5,500 & 8 & 5 & 3 & 7 \\
\hline De 5,501 a 6,500 & 22 & 14 & 2 & 5 \\
\hline Mayor de 10,000 & 111 & 68 & 12 & 30 \\
\hline Total & $\mathbf{1 6 2}$ & $\mathbf{1 0 0}$ & $\mathbf{4 0}$ & $\mathbf{1 0 0}$ \\
\hline
\end{tabular}

Cuadro $\mathrm{N}^{\circ} .1$ Inversión inicial

Universo: 162 negocios formales y 40 negocios informales

Fuente. Datos primarios de encuesta, Mayo 2013. 
Los negocios que comienzan con un presupuesto inicial bajo, se enfocan en invertir su tiempo y talento en lugar de una gran cantidad de dinero.

A continuación Juana Castillo expresa:

"Inicie mi negocio hace doce años con un capital inicial de mil córdobas, con ello compre un quintal de azúcar, uno de arroz, una caja de jabón de lavar ropa, un quintal de frijoles, pan, café y un bidón de aceite, si yo iniciara operaciones el día de hoy, sólo compraría un quintal de arroz para mi negocio. " (Juana Castillo)

\section{Características administrativas de los negocios formales e informales}

El $94 \%$ de los negocios formales y el $93 \%$ de los negocios informales son administrados por sus propietarios. Sin embargo los negocios que cuentan con un administrador ya sea familiar o particular, quien toma las decisiones es el propietario del negocio.

El $38 \%$ de los negocios formales cuenta con trabajadores, de este porcentaje solo el $48 \%$ emplea a una persona, el $58 \%$ contratan a familiares, y un $74 \%$ de los trabajadores son fijos, el resto son contratados por temporada, es decir, navidad, mayo, los días viernes, de acuerdo a las ventas, ya que son días concurridos por los trabajadores.

Un $70 \%$ de los negocios informales no cuentan con trabajadores, como consecuencia de que son negocios pequeños, que solo obtienen ingresos para cubrir las necesidades básicas, por lo tanto no tienen capacidad para contratar a otra persona.

Del $30 \%$ de los negocios informales que cuentan con personal, el $92 \%$ solo emplean a una persona. El 58\% de los trabajadores son familiares de los propietarios, esto se debe a que no confían en terceras personas para emplearlas, y el $42 \%$ son particulares en este caso los propietarios reflejaron que necesitaban a personas que supieran realizar la actividad a la que se dedican (ejemplo taller de mecánica).
El $83 \%$ de los trabajadores son fijos, en un horario de lunes a sábado en su mayoría, y el $17 \%$ de los trabajadores son temporales, es decir que solo asisten en ocasiones, cuando el propietario no puede permanecer en el negocio por otras actividades.

El $72 \%$ de los negocios informales no se han formalizado, debido a que su negocio es muy pequeño y expresan no tener capacidad para pagar impuestos, mientras que el $28 \%$ de estos definitivamente reflejo que no quiere pagar impuestos. (Ver cuadro $\mathrm{N}^{\circ} .2$ )

\begin{tabular}{|l|l|l|}
\hline \multicolumn{1}{|c|}{ Razones } & \multicolumn{1}{c|}{ Frecuencia } & \multicolumn{1}{c|}{$\%$} \\
\hline Negocio muy pequeño & 29 & 72 \\
\hline No quiere pagar impuesto & 11 & 28 \\
\hline Otro & 7 & 18 \\
\hline
\end{tabular}

Cuadro $\mathrm{N}^{\circ}$. 2 Razones de no formalizar los negocios informales.

Universo: 40 encuestados

Fuente: Datos Primarios, Mayo 2013

Uno de los factores determinantes para el crecimiento y consolidación de los nuevos negocios, hoy en día, es su formalización. Por esto, los negocios deben contar con una estructura legal que sea su mejor garantía para mantenerse o expandirse en el mercado.

Al respecto se tienen expresiones como la siguiente:

"Soy comerciante y me dedico a la elaboración de comida, éstas se las ofrezco a los trabajadores de tres fábricas, mi negocio ha ido aumentando, porque antes solo ofrecía almuerzos y ahora por el aumento de la demanda he decidido ofrecer desayunos.

Las ventas han aumentado pero aun así no quiero inscribir mi negocio en la Renta ni en la Alcaldía, porque ese dinero que les voy a dar a ellos los ocupo para ofrecer diversidad de platillos, prefiero ser informal aumentando mis ventas que llenar el bolsillo de funciones. (Pineda, propietaria de negocio informal). 
El 59\% de los negocios formales planifica, elaborando los pedidos, las promociones de venta y afiches, realizando las compras para abastecer el negocio de acuerdo a la demanda de los productos y/o servicios, en cambio solo un $5 \%$ de los negocios informales planifica las actividades de compra (Ver cuadro $\mathrm{N}^{\circ} .3$ )

\begin{tabular}{|l|r|r|r|r|}
\hline Planeación & $\begin{array}{r}\text { Negocios } \\
\text { Formales }\end{array}$ & \multicolumn{1}{c|}{$\%$} & $\begin{array}{c}\text { Negocios } \\
\text { Informales }\end{array}$ & \multicolumn{1}{c|}{$\%$} \\
\hline $\mathrm{Si}$ & 96 & 59 & 2 & 5 \\
\hline No & 66 & 41 & 38 & 95 \\
\hline Total & 162 & $100 \%$ & 40 & $100 \%$ \\
\hline
\end{tabular}

Cuadro $\mathrm{N}^{\circ}$. 3 Planeación de actividades

Universo: 162 negocios formales y 40 negocios informales

Fuente. Datos primarios de encuesta, Mayo 2013.

El $41 \%$ de los negocios formales y el $95 \%$ de los negocios informales no planifican ninguna actividad, debido a la falta de tiempo por lo tanto, van resolviendo las actividades de la manera que se le van presentando.

El $62 \%$ de los negocios formales y el $68 \%$ de los negocios informales no llevan un registro de las operaciones contables, ya que consideran que es un atraso, debido a que no es importante para ellos, porque son los únicos que atienden el negocio.

El $38 \%$ de los negocios formales y el $32 \%$ de los negocios informales, si lleva un registro manual de las operaciones, debido a que es indispensable para el buen funcionamiento de cualquier negocio, permitiéndoles determinar cuáles son los productos que tienen un mayor movimiento, que días se vende más, para así mismo realizar sus pedidos, de acuerdo a la demanda.

A pesar de que estas personas llevan un registro manual de las operaciones, no cuentan con un sistema contable que les permita administrar de una forma más eficaz las actividades comerciales. Al mismo tiempo la falta de conocimiento incide negativamente en el manejo de los recursos económicos, no hacen diferencia entre inversión y gastos personales, por lo que disminuye el capital de trabajo.

"No considero necesario llevar contabilidad de las operaciones en mi negocio, porque los productos que vendo son pocos, sé el precio de cada producto y la ganancia que puedo tener y así determino la rentabilidad de mi negocio" (propietario de negocio Ranchito Alegre).

El sector comercio lo comprenden el $77 \%$ de los negocios formales y el $90 \%$ de los negocios informales, debido a que se vende más los productos alimenticios, ropa, calzado y productos varios.

A las personas se les facilitan más revender que producir, debido a que no cuentan con el capital necesario para invertir en maquinaria, instalaciones, mano de obra, ya que estos son pequeños negocios, que no tienen recursos para transformar, por lo tanto se dedican a comercializar.

En la zona media del distrito III de la ciudad de Estelí predomina la actividad comercial al detalle, en el cual sobre salen las pulperías, las tiendas de ropa y calzado, las farmacias, etc. El giro principal de los negocios formales son las pulperías con el $47 \%$, mientras en los negocios informales predominan los puestos de comida con un $30 \%$, esto se debe a que el personal que labora en estas fábricas necesita desayunar o almorzar y por eso se convierte en el negocio más atractivo para ellos.

El $67 \%$ de los propietarios de negocios formales y $68 \%$ de los propietarios de negocios informales se ven afectados por la existencia de una fuerte competencia, debido a que esta es una zona atractiva para el comercio, han surgido nuevos negocios que tienen mayor capacidad de compra, por lo que sus productos tienen un precio más bajo, ejemplo de ello el Supermercado Pali-Norte y la Farmacia San 
Sebastián, que usan la economía de escala para la comercialización de los productos, por lo que estos negocios se han vistos afectados, disminuyendo así sus ventas.

El 5\% de los negocios informales considera que son afectados por las temporadas lluviosas, debido a que las calles son inaccesibles, lo cual provoca que las personas no puedan asistir a ciertos puestos de ventas.

El $17 \%$ de los propietarios de negocios formales y el $38 \%$ de los propietarios de los negocios informales no consideran importante la publicidad, opinan que no es útil, debido a que crean su negocio como un medio de subsistencia, y se dan a conocer mediante la buena atención a sus clientes. Sin embargo los comerciantes que no consideran importante la publicidad, hacen uso de ella indirectamente, utilizando rótulos para ofertar sus productos y/o servicios.

\begin{tabular}{|l|r|r|r|r|}
\hline Publicidad & $\begin{array}{r}\text { Negocios } \\
\text { Formales }\end{array}$ & \multicolumn{1}{|c|}{$\%$} & $\begin{array}{c}\text { Negocios } \\
\text { Informales }\end{array}$ & \multicolumn{1}{l|}{$\%$} \\
\hline $\mathrm{Si}$ & 135 & 83 & 25 & 62 \\
\hline No & 27 & 17 & 15 & 38 \\
\hline Total & 162 & 100 & 40 & 100 \\
\hline
\end{tabular}

Cuadro $\mathrm{N}^{\circ} .4$ Importancia de la publicidad Universo: 162 negocios formales y 40 negocios informales

Fuente. Datos primarios de encuesta, Mayo 2013.

Aunque el $83 \%$ considere importante la publicidad solo el $22 \%$ de los negocios formales la utiliza, en cambio el $62 \%$ de los negocios informales la considera necesaria pero solo el $25 \%$ utiliza.

El medio publicitario más utilizado en los negocios son las pancartas, porque es un medio barato, con mucha visibilidad y son elaborados por los mismos comerciantes, por lo que no incurren en ningún gasto. El medio menos utilizado es la televisión, ya que es un medio costoso, por lo que no todos los negocios tienen la capacidad para pagarla.
El $33 \%$ de los negocios formales y el $40 \%$ de los negocios informales ofrecen políticas de venta especiales para los trabajadores de las fábricas, entre ellas: crédito disponiendo como facilidad de pago cuotas semanales.

Los negocios de esta zona ofrecen políticas de venta especiales a los trabajadores de las fábricas, debido a que ellos ayudan al progreso de su negocio, además dependen en su mayoría de las compras que estos realizan. El $56 \%$ de los negocios formales otorgan crédito, en cambio en los negocios informales solo el $31 \%$. Los negocios formales tienen mayor capacidad para mantener en existencias sus productos, mientras los trabajadores abonan o cancelan la deuda, por lo que otorgan más crédito.

El $50 \%$ de los negocios formales utilizan las rifas, porque es una manera más rápida y barata que permite captar mayor clientela. El descuento es otra de las promociones de venta que tiene un impacto positivo en los compradores. De los dieciséis negocios informales que realizan promociones de ventas, el $38 \%$ utilizan descuentos y rebajas para aumentar la clientela.

Beneficios que tienen los negocios formales $e$ informales al estar ubicados en las cercanías de las fábricas de tabaco

\begin{tabular}{|l|l|l|l|l|}
\hline $\begin{array}{c}\text { Ingresos en } \\
\text { córdobas C\$ }\end{array}$ & $\begin{array}{l}\text { Negocios } \\
\text { Formales }\end{array}$ & $\%$ & $\begin{array}{c}\text { Negocio } \\
\text { Informales }\end{array}$ & $\%$ \\
\hline $0-10,000$ & 51 & 31 & 25 & 63 \\
\hline $10,001-20,000$ & 29 & 18 & 15 & 27 \\
\hline $20,001-30,000$ & 17 & 10 & 0 & 0 \\
\hline $30,001-40,000$ & 22 & 14 & 0 & 0 \\
\hline $40,001-a$ mas & 43 & 27 & 0 & 0 \\
\hline Total & 162 & 100 & 0 & 0 \\
\hline
\end{tabular}

Cuadro $\mathrm{N}^{\circ} .5$ Ingresos por ventas mensuales Universo: 162 negocios formales y 40 negocios informales.

Fuente. Datos primarios de encuesta, Mayo 2013. 
El $31 \%$ de los negocios formales obtienen de 0 a 10,000.00 córdobas en concepto de ingresos mensuales por venta, en cambio el $63 \%$ de los negocios informales tienen ventas mensuales de 0 $-10,000.00$ córdobas, debido a que algunos llegan a vender solo los días viernes, porque es el día de pago de los trabajadores de las fábricas de tabaco.

Una de las variantes para que los negocios formales sean más rentables, es la variedad de productos, otorgan mayores facilidades de pago, y no dependen principalmente de los trabajadores de las fábricas, ya que también venden $u$ ofrecen sus productos y/o servicios a los habitantes de la zona, por lo que son menos afectados por el despido del personal de las fábricas.

Los negocios que están ubicados en las cercanías de las fábricas de tabaco, tratan directamente con los clientes, les ofrecen crédito porque la mayoría de los trabajadores de las tabacaleras lo solicitan para el día de pago, lo que incide positivamente en la obtención de mayores ingresos.

En el $64 \%$ de los negocios formales y en el $55 \%$ de los negocios informales reinvierte más del $50 \%$ de las utilidades. Los propietarios de estos negocios invierten más del $50 \%$ debido a que necesitan hacer frente a la competencia, teniendo en cuenta que la mayor parte de negocios son pulperías y puestos de comida, por lo que es necesario invertir un alto porcentaje que les permita tener variedad de productos para satisfacer las necesidades del consumidor.

El $54 \%$ negocios formales y el $88 \%$ de los negocios informales son rentables, debido a que están ubicados estratégicamente en las cercanías de las fábricas de tabaco.

Los propietarios de estos negocios se han instalado en esta zona de la ciudad por el potencial económico que existe, principalmente por los trabajadores que laboran en las fábricas de tabaco que ayudan al sostenimiento de estos negocios.

El $85 \%$ de los propietarios de negocios formales y el $95 \%$ de los propietarios de los negocios informales, consideran que el surgimiento de las fábricas de tabaco de la zona media del distrito III, ha influido positivamente para poder establecerse, además los negocios que ya estaban establecidos antes del surgimiento de las fábricas de tabaco reconocen haber tenido un crecimiento significativo en su negocio.

\begin{tabular}{|l|r|r|r|r|}
\hline Incidencia & $\begin{array}{l}\text { Negocios } \\
\text { Formales }\end{array}$ & $\%$ & $\begin{array}{l}\text { Negocios } \\
\text { Informales }\end{array}$ & \multicolumn{2}{l|}{} \\
\hline $\mathrm{Si}$ & 138 & 85 & 38 & 95 \\
\hline No & 24 & 15 & 2 & 5 \\
\hline Total & 162 & 100 & 40 & 100 \\
\hline
\end{tabular}

Cuadro $N^{\circ} .6$ Incidencia de las fábricas de tabaco.

Universo: 162 negocios formales y 40 negocios informales Fuente.

\section{Datos primarios de encuesta, Mayo 2013.}

El $15 \%$ de los propietarios de negocios formales y el $5 \%$ de los propietarios de negocios informales, no creen que las fábricas de tabaco han influido en el desarrollo de su negocio, debido a que están alejados de estas, por lo que los trabajadores no compran en sus establecimientos.

El $36 \%$ de los propietarios de negocios formales y el $58 \%$ de los propietarios de negocios informales crearon su negocio por falta de empleo, al mismo tiempo les permite cuidar de la casa y familia, tomar sus decisiones y ser su propio empleador.

Otra de las variables para la creación de estos negocios es la existencia de ocho fábricas de tabaco que emplean 5,198 personas, por lo que demandan productos y/o servicios, convirtiéndose en el principal atractivo de los comerciantes.

A continuación se tiene un comentario de un propietario de un negocio formal: 
"Si creo que las fábricas de tabaco han influido en el desarrollo de mi negocio, porque la mayoría de mis clientes son trabajadores de dichas fábricas, y por lo tanto si estas cierran operaciones, todos los negocios nos miraríamos afectados, lo que provocaría la quiebra y por ende, el cierre de estos". (Sr. Israel Acuña)

El $96 \%$ de los propietarios de negocios formales y el $65 \%$ de los propietarios de negocios informales, tienen expectativas de crecimiento, por lo que destinan según las encuestas realizadas más del $50 \%$ de las ganancias obtenidas de la actividad comercial, al mismo tiempo utilizan medios publicitarios para darse a conocer, entre ellos las pancartas, el buen servicio al cliente y algunos negocios con mayor poder económico hacen publicidad a través de medios de comunicación locales, ejemplo la televisión y la radio.

\begin{tabular}{|l|r|r|r|r|}
\hline Factores & $\begin{array}{r}\text { Negocios } \\
\text { Formales }\end{array}$ & \multicolumn{1}{c|}{$\begin{array}{c}\text { Negocios } \\
\text { Informales }\end{array}$} & \multicolumn{1}{l|}{$\%$} \\
\hline $\mathrm{Si}$ & 155 & 96 & 26 & $65 \%$ \\
\hline No & 7 & 4 & 14 & $35 \%$ \\
\hline Total & 162 & 100 & 40 & 100 \\
\hline
\end{tabular}

Cuadro No. 7 Expectativas de crecimiento. Universo: 162 negocios formales y 40 negocios informales Fuente: Datos primarios de encuesta, Mayo 2013.

Como se puede observar en la tabla No. 7 los propietarios de los negocios informales tienen menos expectativas de crecimiento, por su falta de visión empresarial, ya que se conforman con mantenerse en el mercado.

Al respecto se tiene la siguiente opinión:

"No tengo expectativas de crecimiento para mi pequeño negocio, porque solo es para obtener otros ingresos, puesto que yo tengo mi trabajo fijo y acá solo vengo a vender los días viernes, que es el día de pago de los trabajadores". (Propietario de negocio informal).
En base al análisis de la información obtenida por medio de las encuestas y entrevistas se realizó un análisis de las principales fortalezas, oportunidades, debilidades y amenazas de los negocios formales e informales de la zona media del distrito III de la ciudad de Estelí.

En su mayoría los propietarios de estos negocios son dueños del local, evitando el gasto de alquiler, al mismo tiempo no se ven con la necesidad de incrementar el margen de ganancia, lo cual hace que los productos $y / o$ servicios que ofrecen sean más competitivos, además tratan directamente con el cliente, permitiéndoles conocer sus gustos y preferencias.

Las oportunidades que le ofrece el mercado es la posición estratégica, debido a la afluencia de personas, no solo por los habitan en la zona, sino por los trabajadores y la tendencia de las fábricas de tabaco a aumentar su personal.

La mayoría de los negocios tanto formales como informales no cuentan con garantías para solicitar un préstamo a bancos o financieras, limitándolos a ofrecer una mayor variedad de productos y hacer uso de la publicidad masiva.

Otra debilidad es que no llevan registros contables, debido a que carecen de conocimientos, o porque no disponen del tiempo necesario para llevar un registro contable.

La mayor amenaza que poseen estos negocios es la inestabilidad laboral de los trabajadores en las fábricas, además en el caso de los negocios informales se ven obligados a someterse a las regulaciones municipales.

Las estrategias propuestas en la investigación para los negocios formales son:

1. Solicitud de un crédito bancario.

2. Establecimiento de un registro de las operaciones comerciales.

3. Promover el uso de la publicidad. 
Las estrategias propuestas en la investigación para los negocios informales son:

1. Legalización del negocio ante las autoridades competentes.

2. Solicitud de un crédito bancario.

3. Establecimiento de un registro de las operaciones comerciales.

\section{CONCLUSIONES Y RECOMENDACIONES}

Los negocios formales e informales de la zona media del distrito III de la ciudad de Estelí, actualmente se ven afectadas por el aumento considerable de la competencia, la poca diversificación de la inversión, la no utilización de registros de las operaciones comerciales y la falta de financiamiento.

Los propietarios de estos negocios no planifican las actividades económicas, es decir, que cantidad de productos comprar, que marcas o a que proveedores, lo que conlleva a la inadecuada toma de decisiones, compran demasiados productos que no tiene un movimiento ágil o productos que tienen una corta duración.

Las personas son motivadas a emprender su negocio por la obtención de ingresos propios, representado con el $63 \%$ de propietarios de negocios formales y $68 \%$ de los propietarios de negocios informales e influenciados por el mayor número de clientes de la zona media.

El $94 \%$ de los negocios formales son administrados por su propietario y solo el $2 \%$ son administrados por un particular.

El principal factor que incide positivamente en la rentabilidad de los negocios es la ubicación estratégica, porque, al existir estas fábricas de tabaco, los trabajadores necesitan comprar alimentos, bebidas, golosinas, ropa, etc. Al mismo tiempo la generación de empleo permite a las personas tener una mayor disponibilidad de ingresos.
Como se demuestra la hipótesis de investigación se cumple, ya que el $95 \%$ de los encuestados de negocios informales y el $85 \%$ de los negocios formales, respondió que se establece en esta zona, debido a la cantidad de trabajadores que emplean las fábricas de tabaco.

En relación a los resultados del trabajo investigativo sobre la incidencia de las fábricas en el surgimiento de los negocios, se propusieron las siguientes recomendaciones:

A los propietarios de negocios formales e informales de la zona media del distrito III de la ciudad de Estelí, mejorar la calidad en la atención a los clientes, planificar las actividades comerciales.

Al Ministerio de Economía Familiar, Comunitaria y Cooperativa, al Ministerio de Fomento, Industria y Comercio (CAMIPYME), MIFIC/INPYME y al Programa de Desarrollo de la Micro, Pequeña y Mediana Empresa Nicaragüense (PROMIPYME), que realicen capacitaciones sobre registros contables, emprendedurismo y motivación, para que los microempresarios adquieran dichos conocimientos que son indispensables para permanecer en el mercado.

A los propietarios de empresas tabacaleras realizar convenios con los propietarios de comercios para que sus trabajadores tengan precios más accesibles en sus compras.

\section{BIBLIOGRAFÍA}

Andersen. A. (1997). Economía y Negocios. (1a ed.).España. ESPASA. Iera. Edición).

ARÉVALO, N. GUTIÉRREZ, J. y MORENO, D. (2012). Impacto económico generado por el empleo a los trabajadores del área de producción en la empresa manufacturera de tabaco Drew Estate tobacco company, de la ciudad de Estelí en 
el año 2012. Tesis de monografía. Estelí, FAREMEstelí, 77 pág.)

CASTILLO B. (2007). Diagnóstico sobre derechos humanos, laborales y de género de mujeres que laboran en las fábricas de tabaco de la ciudad de Estelí. Diagnóstico. Estelí, Movimiento de Mujeres Trabajadoras y Desempleadas MEC.

MONTALVÁN, E. y RODRÍGUEZ, A. (2011). Situación económica y social que presenta el comercio informal en la avenida central de la ciudad de Estelí en el año 2011. Tesis de monografía. Estelí, FAREM-Estelí, 89 pág.)

SALINAS, J. y HERNÁNDEZ, Y. (2009). Caracterización económica y legal del comercio informal de la ciudad de Condega 2009. Tesis de monografía. Estelí, FAREM-Estelí, 42 pág.)

COMISIÓN NACIONAL DE ZONAS FRANCAS. (2005). Reglamento del Decreto de Zonas Francas Industriales. [En línea]. [Consultado Abril del 2013]. http://legislacion.asamblea.gob.ni/Normaweb

MIFIC. (2008). Ley de Promoción, Fomento y Desarrollo de la Micro, Pequeña y Mediana Empresa (LEY MIPYME). [En línea]. [Consultado Abril del 2013]. Disponible en: http://legislacion. asamblea.gob.ni/Normaweb. 